\title{
Meeting Their Fullest Potential: The Beliefs and Teaching of a Culturally Relevant Science Teacher
}

\author{
Charlease P. Kelly-Jackson ${ }^{1}$, Tambra O. Jackson ${ }^{2}$ \\ ${ }^{1}$ Kennesaw State University, Kennesaw, Georgia; \\ ${ }^{2}$ University of South Carolina, Columbia, USA. \\ Email: ckellyja@kennesaw.edu, tambra.jackson@sc.edu \\ Received February 12 ${ }^{\text {th }}$, 2011; revised March 19 $9^{\text {th }}$, 2011; accepted March $28^{\text {th }}, 2011$.
}

\begin{abstract}
As elementary and middle school children of color continue to score poorly on science standardized tests, culturally relevant teaching has been shown to be an effective approach to addressing the social and academic needs of students from diverse backgrounds. In this article, we illustrate how the theory of culturally relevant pedagogy is embraced in the teaching beliefs of a sixth grade science teacher in a rural, low socioeconomic, predominantly African American school. The findings from a qualitative case study reveal beliefs and teaching practices consistent with three major tenets of culturally relevant pedagogy: conceptions of self and students; social relations; and perceptions of knowledge (Ladson-Billings, 2009). This study builds upon the culturally relevant pedagogy knowledge base by illustrating the tenets of this theory in the beliefs and teaching practices of a sixth grade science teacher.
\end{abstract}

Keywords: Culturally Relevant Pedagogy, Science Education, Teacher Beliefs, African American Students

\section{Introduction}

Elementary and middle school children of color continue to score poorly on science standardized tests. According to the National Assessment for Educational Progress [NAEP] (2009) and the National Center for Education Statistics (2003, 2007, 2010), African American and Hispanic/Latino students are significantly behind their White counterparts in terms of grade level competence in reading, math, history, geography, and science. More specifically, science standardized test data show a history of significant achievement gaps among students of color and English language learners (Lee \& Fradd, 1998; Mullis, Dossey, Campbell, Gentile, O’Sullivan, \& Latham, 1994; National Center for Educational Statistics, 2002; National Science Foundation, 1994; Parsons, 2008). In fact, their poor achievement becomes more and more visible as they move further in school (Parsons, 2008). The National Assessment for Educational Progress (2009) reports 42\% of African American fourth graders, 59\% African American eighth graders, and 67\% African American twelfth graders performed below basic on their science proficiency exams.

Research suggests that challenges in science learning increase for students who do not bring the same views and ways of knowing science from their culture as are taught in schools (Aikenhead \& Otsujui, 2000; Atwater, Freeman, Butler, \& DraperMorris, 2010; Bryan \& Atwater, 2002; Barba, 1993; Bianchini, Cavazos \& Rivas, 2003). According to Atwater (1994), "more traditional ways of teaching science might not be as effective with underrepresented groups in science as are some of the active, relational and holistic approaches” (p. 563). Learning to teach science in an equitable manner in contemporary contexts can be complex and challenging (Bianchini \& Brenner, 2010; Bianchini et al., 2003). While numerous factors influence teachers' decisions about the content they teach, how they teach it and what materials will actively engage students with the content (Weiss \& Pasley, 2004), science learning and achievement occur when science is presented in a mainstream fashion in concert with valuing the relevance of students' everyday lives (Aikenhead, 1996; Bianchini \& Brenner, 2010).

Culturally relevant pedagogy has been shown to be an effective approach to addressing the social and academic needs of students from diverse backgrounds especially at a time when students of color continue to fare poorly in U.S. schools (Gay, 2000; Howard, 2010; Ladson-Billings, 2009; Patterson, 1997). A growing body of literature exists examining culturally relevant pedagogy in various disciplines such as literacy, history, geography, art and mathematics (Baker \& Digiovanni, 2005; Boutte \& Hill, 2006; Gutstein, 2003; Jackson \& Boutte, 2009; Ladson-Billings, 1992; Stinson, 2004; Tate, 1995; Thomas, 2006). Although literature addressing equitable science teaching and practices is emerging (Aikenhead \& Otsujui, 2000; Atwater, et al., 2010; Bianchini \& Brenner, 2010; Lee \& Buxton, 2008; Lee \& Luykx, 2007; Luykx \& Lee, 2007; Sadler, Amirshokoohi, Kazempour, \& Allspaw, 2006), attention to culturally relevant teaching in science is near absent in the literature (Boutte, Kelly-Jackson, \& Johnson, 2010). In this article, we illustrate how the theory of culturally relevant pedagogy, which speaks to the notion that classroom instruction should be more relevant to the students' cultural orientations and experiences, is enacted in the teaching beliefs of a sixth grade science teacher in a rural, low socioeconomic, predominantly African American school. Our goal is to demonstrate how this pedagogy is embraced in the beliefs of the teacher, which in turn, become enacted in her teaching practice. We begin by explaining the theory of culturally relevant teaching and how it is visualized in the science classroom.

\section{Teaching Science to Diverse Students}

Research on the teaching science to diverse populations points to promising practices. Lee and Fradd (1998) note that promoting science to students of color and non-English language backgrounds involves understanding the nature and practice of science as it relates to the students' language and cul- 
tural experiences. The comprehension of scientific knowledge and terminology is a key component of knowing science. Students' prior knowledge and experiences are crucial components in acquiring new information (Driver, Asoko, Leach, Mortimer \& Scott, 1994; Posner, Strike, Hewson, \& Gertzog, 1982). Studies conducted by Rosebery and colleagues (Rosebery, Warren, \& Conant, 1992; Warren, Rosebery, \& Conant, 1989), emphasized the effects of "doing science" among Haitian and Hispanic students. The essential idea in the Cheche Konnen project was to involve students who had little to no experience engaging in formal science practices. The studies used openended scientific inquiry and analyzed students' communication patterns as they learned new science skills and content. Researchers focused on changes in the students' conceptual knowledge and the use of hypotheses, experiments, and explanations. Results indicated that students bring different levels of knowledge into the science classroom; therefore, it is important to show relevance.

Drawing upon students' prior experiences with the content helps teachers link the science learning goals with what students already know (Atwater, 1994; Barba, 1993; Bianchini \& Brenner, 2010; Lee \& Fradd, 1998; Matthews \& Smith, 1994). Teaching science and encouraging science learning requires teachers to have 1) "an understanding and appreciation of students' languages and cultural experiences, 2) scientific knowledge and habits of mind, and 3) abilities to relate science to students' background experiences” (Lee \& Fradd, 1998: p. 18). In sum, teachers have to integrate students' language and culture with their science content knowledge in order to provide all students with quality science (Lee, 2003).

Culturally relevant teaching is a theoretical framework for education that embraces the cultural capital of students from culturally diverse backgrounds (Gay, 2000; Ladson-Billings, 2009; Morrison, Robbins, \& Rose, 2008). It uses "the cultural knowledge, prior experiences, frames of reference, and performance styles of ethnically diverse students to make learning encounters more relevant to and effective for them" (Gay, 2000: p. 29). While culturally relevant pedagogy is a part of the broader conversation on equitable teaching and practices for historically marginalized youth, it is a theory that entails specific tenets which work in tandem. Culturally relevant teachers must have an ability to develop students academically, a willingness to nurture and support cultural competence, and the ability and desire to foster the development of a sociopolitical or critical consciousness (Ladson-Billings, 2009). In order to engage in this kind of teaching, teachers have to embrace a pedagogical stance inclusive of particular kinds of knowledge, skills, and dispositions that encompasses 1) their conceptions of self and others, 2) the manner in which social relations are structured, and 3) their conceptions of knowledge (LadsonBillings, 2009). Culturally relevant teachers see themselves as members of the community and teaching as a way to give back to the community. They also believe that all their students are capable of academic success. When cultivating social relations in their classrooms, culturally relevant teachers demonstrate a connectedness with all of the students and encourage students to learn collaboratively and be responsible for one another. Finally, when it comes to conceptions of knowledge about the curriculum and content, culturally relevant teachers view knowledge as shared, recycled and constructed. They promote the idea that knowledge is not static and must be viewed critically.

Research efforts that focus on diversity and equity issues in science instruction have focused on students from diverse languages and cultures, but few specifically place attention on culturally relevant pedagogy in science classrooms. Furthermore, since science teachers are one of the most influential factors on science learning (Atwater, 2000), this case study uses the theoretical lens of culturally relevant pedagogy to examine the beliefs and teaching of a teacher of African American students in a rural, sixth grade science classroom. The analysis highlights the ways in which the teacher embraces notions of culturally relevant pedagogy as her primary pedagogical stance in her science teaching.

\section{Method}

The research reported in this article is a case study from a larger multiple method project which examined the beliefs and perceptions of middle school science teachers towards culturally relevant teaching. A possible pool of teachers was identified using the school and district webpages. The participants represented middle school science teachers (grades 6 - 8) in four counties included in what is referred to as the "Corridor of Shame." This is a group of rural schools, in proximity to U.S. Interstate 95 in South Carolina, that serve predominantly lowincome and poor African American students (Ferillo, 2006). Eight participants agreed to participate and completed a 2-part Likert-type scale questionnaire developed by Phuntsog (2001). The items tapped into beliefs and dispositions considered to be important characteristics and issues for culturally relevant teaching inclusive of being culturally literate; self-reflective analysis of one's attitudes and beliefs; caring, trusting, and inclusive classroom; respect for diversity; and transformative curriculum to create social change (Phuntsog, 2001).

Teachers were then asked to participate in a focused interview informed by their responses to the questionnaire. The one hour focused interviews were used to corroborate data ascertained from the questionnaire. Four teachers agreed to be interviewed. The interviews focused on 1) participants' personal histories and how they came to choose teaching as their profession; 2) their beliefs about culturally relevant teaching and how their experiences have shaped their teaching practices; 3) challenges teachers face while teaching and how those challenges relate (if at all) to diversity

After analyzing data from the questionnaire and focused interviews, the first author identified one teacher as representative of the literature on culturally relevant teaching. The author employed case study methodology which best suited the primary goal of this phase of the project which was to examine the phenomenon of culturally relevant science teaching in a specific context (African American students in a low socioeconomic rural setting). Using a case study approach allowed the researchers to gain an understanding of a complex social phenomenon (in this case, culturally relevant teaching) while capturing a holistic and meaningful view of everyday activities (Yin, 2008). Our main inquiry was: What does culturally relevant science instruction for African American students look like in a sixth grade science classroom? In this article, we specifically focus on findings that speak to how a teacher's beliefs aligned with culturally relevant theory support her teaching practice.

\section{Participant}

Sammie (pseudonym) was a 36 year old African American female science and social studies teacher in her fifth year of teaching. She attended the state's public schools and obtained her Master of Arts degree in teaching from a historically black 
institution. She entered the teaching profession with a range of life experiences, including previous work experience in accounting. She was considered by her colleagues and administrators to be an excellent teacher and had been recognized as the school's "Teacher of the Year." Sammie also served as the varsity cheerleading coach. During the time this study was conducted, Sammie was seeking a terminal degree in administration.

\section{Context}

Sammie taught at a predominantly African American middle school along Interstate 95 in South Carolina also referred to as the "Corridor of Shame" (Ferillo, 2006). The school consists of grades 6 - 12 and accommodates approximately 411 students. The State Department of Education in South Carolina recognizes and provides awards not only for high levels of student achievement but also to schools attaining high levels of absolute performance and/or to schools attaining high rates of improvement in the areas such as student attendance, teacher attendance, and/or student dropout rates. The school at which Sammie taught ranked below average for the past three years prior to the study in their absolute rating. Below average means the school was in jeopardy of not meeting the standards for progress toward the South Carolina Performance Goals. However, the school received an award two years prior to the study for its improvement rating on the State's Report Card from the State Department of Education as a Red Carpet School in 2008. During the year this study took place, the school's scores on its state's standardized test exceeded the state's average in sixth grade mathematics and social studies, in seventh grade mathematics and English language arts, and in eighth grade English language arts. While the school as a whole was making progress and great strides in the areas of math, English language arts, and social studies, it was not fairing as well in the content area of science.

\section{Data Collection}

In addition to data garnered earlier in the project, the first author conducted three classroom observations of Sammie's teaching and mentoring both during school and after-school hours. The researcher chose to visit Sammie's classroom at different points in the school day every two weeks over six weeks. Extensive fieldnotes were taken during these three to four hour observations in order to gain a more in-depth understanding as to how Sammie goes about her everyday life as a culturally relevant science teacher (Emerson, Fretz, \& Shaw, 1995). In addition to fieldnotes, audio files from the observations were used and transcribed in order to capture student-student and student-teacher interactions. Artifacts (e.g. test scores, philosophy of teaching and learning, lesson plans, students assignments) were also collected during visits to the school. The goal of this portion of data collection was to garner multiple sources of evidence (e.g. direct observation, participant-observation, documentation, artifacts) commonly used in case study methodology (Yin, 2008).

\section{Data Analysis}

The data were analyzed using culturally relevant pedagogy as a theoretical framework. Data were examined for the broad dimensions and recurring discourse patterns relevant to culturally relevant pedagogy. After the interview and each observation, post interview and post observation forms (Jay, 2006) were completed to reflect upon what was shared or not shared by the interviewee. The coded data were organized under subheadings such as communication, cultural literacy, teacherfacilitator, inclusive classroom environment, and community of learners.

\section{Findings}

Helping Students Meet Their Fullest Potential: Sammie's Conceptions of Herself and Her Students

Ladson-Billings $(1995,2009)$ posits that culturally relevant teachers have a clear understanding of themselves and others. Culturally relevant teachers have a keen awareness of how powerful the role and responsibility of teachers are in the lives of students. They are clear about their purpose as teachers in the lives of their students and in the profession. During the interview Sammie was asked why she chose teaching as a career. She responded by noting that teaching was not her first choice as a profession. She mentioned that she wanted to explore a career different from her other family members (most of whom were teachers) and decided to go into accounting. Sammie believed that teaching was always in her heart and eventually something inside her led her to it. She said with a smile, "I realized that this is something I am supposed to be doing." Sammie described herself as a humble individual who teaches from the heart:

I look at the child for who that child can become; because we're gonna have to depend on these children one day. But I humble myself and try not to get too religious or spiritual, 'cause I am not a religious person. But you have to look at your calling. If this is something you are called to do, and you know the person who called you to do it, and you know that person who called you always expects something higher, then that's what you have to do.

Sammie has a keen sense of purpose in her work as a science educator. Though she does not consider herself to be a very religious person, she is very clear about having been called to be a teacher. In other words, she could have continued with the career path of being an accountant, but she has greater sense of purpose in her work as a teacher. She is very clear about her beliefs about students and her role in fostering their growth:

I believe that each child is a unique individual who needs a secure, caring, and stimulating atmosphere in which to grow and mature emotionally, intellectually, physically, and socially. It is my desire as an educator to help students meet their fullest potential in these areas by providing an environment that is safe, supports risk-taking, and invites a sharing of ideas.

In addition to having a strong sense of purpose for teaching, Sammie has strong convictions about importance of teaching and learning. In her written philosophy of teaching, she notes:

Teaching and learning are two of the most important activities most people ever engage in. Our capacity to grow in wisdom as well as stature is what makes us human. Teaching is a lifelong process of learning about new philosophies and new strategies, learning from parents and the community, learning from colleagues, and especially learning from the students. Teaching provides an opportunity for continual learning and growth. One of my hopes as an educator is to instill a love of learning in my students, as I share my own passion for learning with them. I feel there is a need for compassionate, strong, and dedicated individuals who are excited about working with children.

Sammie positions herself a learner, and feels the need to model her passion for learning to her students. Sammie had 
several books displayed on her desk that exhibit her commitment to learning and self-improvement. Included amongst the books were titles such as: Teaching Matters: Motivating and Inspiring Yourself; Planting Seeds of Hope: How to Reach a New Generation of African Americans with the Gospel; Do you Know Enough about Me to Teach me: A Student's Perspective; and Teaching to Capture and Inspire all Learners: Bringing your Best Stuff Everyday. Sammie's selection of texts reveals strong messages about her beliefs around her teaching, and she publicly displays these books for her students to understand her perspective.

You Have the Right to...: Sammie's Beliefs and Practices of Social Relations

Typically, the relationship between a teacher and a student is fixed and tends to show the teacher as the leader. The students listen while the teacher speaks; the student works as the teacher assigns. Culturally relevant pedagogy purports the notion of a teacher-student relation that is fluid and extends to interactions beyond the classroom. In this relationship the teacher demonstrates a connectedness with all students and encourages students to learn collaboratively (Ladson-Billings, 2009).

While observing Sammie's classroom, several posters around the room portrayed beliefs about learning collaboratively and taking responsibility for others in the learning community. The posters exuded the ideas of learning, teaching, and playing together as a community while respecting each others feelings, thoughts, and actions in the process. One poster, titled Rights and Responsibilities, read:

You have the right to a safe environment./You have the right to follow safety rules./You have the right to voice your opinion./ You have the right to respect the opinions of others./You have the right to use school books, materials, and equipment./You have the right to take care of all school materials./You have the right to fair treatment./You have the right to treat others fairly./ You have the right to a good education./You have the right to do your best.

The messages on this poster and others encouraged students to take ownership of and responsibility for their own learning and the learning of others. Though all of the statements begin with the clause "You have the right to," the poster's title indicates they also have a responsibility to create the conditions they are entitled to.

Sammie's beliefs about collaborative learning were also evidenced in the kinds of assignments and tasks she designed for her students. She regularly expected them to teach each other and take responsibility for each other. A portion of one of her lesson plans reads:

Have student A to turn to his/her partner and tell the difference between a chemical and physical change. Have student $B$ to turn to his/her partner and give three examples of physical changes and three examples of chemical changes.

Imagine you are teaching a group of younger students about the difference between physical and chemical changes. One student claims the change from liquid to water vapor is chemical. Write a brief paragraph of what you would say to convince the student otherwise.

Sammie's students regularly worked in groups and pairs. In fact, the arrangement of the students' desks encouraged cooperation. The desks were grouped in sets of four. While this spatial arrangement is used in many classrooms around the nation, there is generally no real cooperation taking place amongst students. Unfortunately, many teachers use this kind of seating arrangement in correlation to ability grouping. In the interview, Sammie noted that each student has a specific role in each group and it takes the cooperation of each member to make the group a success.

During one observation, the first author noticed a female student ironing cheerleading skirts. When queried, Sammie explained that she was the varsity cheerleading coach and that her role as a teacher extends beyond the science classroom. Sammie went on to explain that the girls hang out in her classroom on game nights until the game begins. She noted, "It's safer for them to stay on campus and it keeps them out of trouble. Too much can happen if they leave campus. The 'cheer moms' take turns bringing snacks for the girls so they will not have a reason to leave”.

The relationship Sammie had with her students resembled that of an extended family. She was firm, yet flexible about classroom expectations and she helped students understand the meaning of consequences. Sammie lived nearly 30 minutes away from the school, yet she chose to be involved with her students beyond the realms of the science classroom through cheerleading. Her role as the cheerleading coach demonstrates her efforts to connect with her students outside the science classroom.

Discovering for Themselves: Sammie's Perceptions of Knowledge

Often times, science is relegated and viewed as a discipline that is factual in nature. It is easy for teachers to fall into the trap of teaching science as a collection of facts to be memorized. Moreover, in many science classrooms, students are taught that science is acultural and void of any connections to cultural and social identities and communities. Culturally relevant teaching, however, "attempts to help students understand and participate in knowledge-building” (Ladson-Billings, 2009: p. 88). Teachers show students that knowledge is continuously recreated, and it is not static or unchanging.

Sammie encourages students to think critically when they search for understanding. Students' assignments clearly depict her efforts to help them develop their capacity to think critically as each student in Sammie's class is considered a scientist. She believes students "need the opportunity to discover for themselves and practice skills in authentic situations.” Because she supports the hands-on approach in the science classroom, Sammie believes such an approach "creates an opportunity for individual discovery and construction of knowledge to occur." Sammie facilitated her students in a hands-on activity entitled "Ch...Ch...Ch...anges" focused on physical and chemical changes and properties. During the lab activity, each group was allowed to rotate to eight stations (labeled A-H) to make observations, record data, and draw conclusions. The stations involved the following inquiry processes:

Station A: Observe eggshell pieces after placed in vinegar; Station B: Observe the change of water after adding drops of food coloring; Station C: Observe changes that occurred after a test tube with sugar is heated; Station D: Observe and compare a penny that was left in lemon juice overnight to one in water; Station E: Observe changes in baking soda when water is added; Station F: Observe Plaster of Paris that was combined with water; Station G: Measure copper sulfate, add to water; and observe changes when an iron nail is added to the copper solution; and Station H: Observe milk when vinegar is added.

To assist students in building their ideas and discussions, the following questions were posed to each group as they engaged in the lab activity.

What are some characteristics of physical changes? What are some characteristics of chemical changes? State the main difference between a physical and a chemical change. Synthe- 
size your responses. Create a double bubble that compares and contrasts physical and chemical changes. Which senses did you use to make observations during this lab? How might you use scientific instruments to extend your sense in order to make more observations?

As groups reported their findings to the entire class, they were allowed to defend their positions if not all groups agreed or observed similar changes.

Sammie believes that it is of equal importance to provide students with the opportunity to study things that are meaningful and relevant to their lives and interests. She knows her students learn better through hands on activities that are relevant to their daily lives. Many of the learning tasks are designed encompassing elements of the outside world and students' lives. In Sammie's philosophy of teaching, she describes her ideal science curriculum:

Developing a curriculum around student interests fosters intrinsic motivation and stimulates the passion to learn. One way to take learning in a direction relevant to student interest is to invite student dialogue about the lesson and units of the study. Given the opportunity for input, students generate ideas and set goals that make for much richer activities than I could have created or imagined myself. When students have ownership in the curriculum, they are motivated to work hard and master the skills necessary to reach their goals.

Having students engage in the construction of knowledge shows them that they are scientists. They do not just read about scientists. They also get the opportunity to be scientists. And in being scientists they have the opportunity to make sense of their previous understandings of science concepts with what they are doing in their labs as well as make connections to their everyday lives.

\section{Discussion and Implications}

Teachers who approach teaching from a culturally relevant standpoint demonstrate three types of beliefs and ideologies in their practice. The first dimension of culturally relevant pedagogy is teachers' conceptions of themselves and others. Sammie's conceptions of herself and her students are consistent with culturally relevant pedagogy and the notions of understanding one's purpose for teaching and the importance of teachers in the lives of students as well as the community. Sammie had high regard for her students, and she believed that she was part of the community and her teaching was a way of giving back. She was completely aware of the image of failure that society held for her African American students, especially in the area of science. Despite the school's below average rating in science, Sammie was convinced that her students could achieve and she saw herself as a vital part of the learning process.

Culturally relevant teachers purposefully create social relations with their students and amongst students that supports community and collaborative learning. Sammie connected with her students, and for some, extended their relationship beyond the science classroom. The rapport she establishes with students let them know that they had a right to expect the best from her; however, they also had the responsibility to give their best. This stance is especially important in the science classroom given the poor performance of students of color in science. Culturally relevant teachers do not allow students to fail. Accepting anything less than students' best is not an option.

Lastly, unlike assimilationist teaching which assumes that "students come to class with certain skills and suggests that it is impossible to teach those who are not of a certain skill level" (Ladson-Billings, 2009: p. 104), culturally relevant teachers help students develop necessary skills by meeting students where they are. Culturally relevant teachers position knowledge as being continuously recreated and students as constructors of knowledge. Sammie created a learning space in her classroom where students were expected to explore and be involved in hands-on inquiry and investigations. Similar to the work of Rosebery and colleagues (Rosebery, Warren, \& Conant, 1992; Warren, Rosebery, \& Conant, 1989), Sammie's students had an opportunity to "do science" and embrace an identity as scientists.

This project builds upon and supports the work of scholars (Gay, 2000; Howard, 2010; Ladson-Billings, 2009) who argue that students from culturally diverse backgrounds are capable learners and the content taught in the classroom should be grounded in cultural contexts consistent with their experiences and values. This article adds to the knowledge base of culturally relevant pedagogy by illustrating the tenets of this theory in the teaching beliefs and practices of a sixth grade science teacher. We suggest that one's pedagogical stance is just as important as content competency in effectively teaching science to students of color.

\section{References}

Aikenhead, G. (1996). Science education: Border crossing into the subculture of science. Studies in Science Education, 26, 1-52.

Aikenhead, G., \& Otsujui, H. (2000). Japanese and Canadian science teachers' views on science and culture. Journal of Science Teacher Education, 11, 277-299.

Atwater, M. (2000). Equity for Black Americans in precollege science. Science Education, 84, 154-179.

Atwater, M., Freeman, T., Butler, M., \& Draper-Morris, J. (2010). A case study of science teacher candidates understandings and actions related to the culturally responsive teaching of "other" students. International Journal of Environmental \& Science Education, 5, $287-$ 318.

Baker, P., \& Digiovanni, L. (2005). Narratives on culturally relevant pedagogy: Personal responses to the standardized curriculum. Current Issues in Education, 8. http://cie.ed.asu.edu/volume8/number22/

Barba, R. (1993). A study of culturally syntonic variables in the bilingual/bicultural science classroom. Journal of Research in Science Teaching, 30, 1053-1071.

Bianchini, J., \& Brenner, M., (2010). The role of induction in learning to teach toward equity: A study of beginning science and mathematics teachers. Science Education, 94, 164-195.

Bianchini, J., Johnston, C., Oram, S., \& Cavazos, L. (2002). Learning to teach science in contemporary and equitable ways: The successes and struggles of first-year science teachers. Science Education, 87, 419-443.

Bianchini, J., Cavazos, L., \& Rivas, M. (2003). At the intersection of contemporary descriptions of science and issues of equity and diversity: Student teachers' conceptions, rationales, and instructional practices. Journal of Science Teacher Education, 14, 259-290. doi:10.1023/B:JSTE.0000009550.91975.76

Boutte, G. S., \& Hill, E. L. (2006). African American communities: Implications for culturally relevant teaching. The New Educator, 2, 311-329. doi:10.1080/15476880600974875

Boutte, G., Kelly-Jackson, C., \& Johnson, G. L. (2010). Culturally relevant teaching in science classrooms: Addressing academic achievement, cultural competence, and critical consciousness. International Journal of Multicultural Education, 12, 1-20.

Bryan, L., \& Atwater, M. (2002), Teacher beliefs and cultural models: A challenge for science teacher preparation programs. Science Education, 86, 821-839.

Driver, R., Asoko, H., Leach, J., Mortimer, E., \& Scott, P. (1994). Constructing scientific knowledge in the classroom. Educational Re- 
searcher, 23, 5-12.

Emerson, R. M., Fretz, R. I., \& Shaw, L. L. (1995). Writing ethnographic fieldnotes. Chicago: The University of Chicago Press.

Ferillo, B. (2006). Corridor of shame: The neglect of South Carolina's rural schools. Columbia, SC: Ferillo \& Associates, Inc.

Gay, G. (2000). Culturally responsive teaching. New York: Teachers College Press.

Gutstein, E. (2003). Teaching and learning mathematics for social justice in an urban, Latino school. Journal for Research in Mathematics Education, 34, 37-73. doi:10.2307/30034699

Howard, T. (2010). Why race and culture matter in schools. New York: Teachers College Press.

Jackson, T. O., \& Boutte, G. S. (2009). Liberation literature: Positive cultural messages in children's and adolescent literature at Freedom Schools. Language Arts, 87, 108-116.

Jay, M. (2006). Race in education, anti-racist activism and the role of white colleagues: Listening to the voices of African American educators. Available from ProQuest Dissertation and These Database (UMI No. 3219468).

Ladson-Billings, G. (1992). Reading between the lines and beyond the pages: A culturally relevant approach to literacy teaching. Theory into Practice, 31, 312-320. doi:10.1080/00405849209543558

Ladson-Billings, G. (1995). Toward a theory of culturally relevant pedagogy. American Educational Research Journal, 32, 465-491.

Ladson-Billings, G. (2009). The dreamkeepers (2nd ed.). San Francisco: Jossey-Bass.

Lee, O. (2003). Equity for linguistically and culturally diverse students in science education: A research agenda. Teachers College Record, 105, 465-489. doi:10.1111/1467-9620.00247

Lee, O., \& Buxton, C. A. (2008). Science curriculum and student diversity: Culture, language, and socioeconomic status. The Elementary School Journal, 109, 123-137. doi:10.1086/590522

Lee, O., \& Fradd, S. (1998). Science for all, including students from non-English-language backgrounds. Educational Researcher, 27, 1221.

Lee, O., \& Luykx, A. (2005). Dilemmas in scaling up educational innovations with nonmainstream students in elementary school science. American Educational Research Journal, 42, 411-438. doi:10.3102/00028312042003411

Luykx, A., \& Lee, O. (2007). Measuring instructional congruence in elementary science classes: Pedagogical and methodological components of a theoretical framework. Journal of Research in Science Teaching, 44, 424-447. doi:10.1002/tea.20127

Matthews, C., \& Smith, W. (1994). Native American related materials in elementary science instruction. Journal of Research in Science Teaching, 31, 363-380.

Morrison, C. A., Robbins, H. H., \& Rose, D. G. (2008). Operationalizing culturally relevant pedagogy: A synthesis of classroom-based research. Equity \& Excellence in Education, 41, 433-452. doi:10.1080/10665680802400006

Mullis, V., Dossey, J., Campbell, J., Gentile, C., O’Sullivan, C., \& Latham, A. (1994). NAEP 1992 trends in academic progress. Washington, DC: Educational Testing Service, under contract with the National Center for Education Statistics, Office of Educational Research and Improvement, US Department of Education.
National Assessment of Educational Progress (NAEP) (2009). Nations Report Card-Science Assessment. US Department of Education, Institute of Education Sciences, National Center for Education Statistics.

National Center for Education Statistics (2003). Condition of education 2003: Indicator 13 geography performance of students in grades 4, 8, and 12 \& indicator 14 US history performance of students in grades 4, 8, and 12. Washington, DC: US Department of Education.

National Center for Education Statistics (2007). Condition of education 2007: Indicator 13 science performance of students in grades 4, 8, and 12. Washington, DC: US Department of Education.

National Center for Education Statistics (2010). Condition of education 2010: Indicator 10 reading achievement gaps \& Indicator 12 mathematics achievement gaps. Washington, DC: US Department of Education.

National Science Foundation (NSF) (1994). Women, minorities, and persons with disabilities in science and engineering: 1994 (NSF-94333). Arlington, VA: Author.

Parsons, E. (2008). Learning contexts, black cultural ethos, and the science achievement of African American students in an urban middle school. Journal of Research in Science Teaching, 45, 665-683. doi:10.1002/tea.20240

Patterson, F. (1997). The African American education data handbook: Volume II. Preschool through high school education. Baltimore: Frederick D. Patterson Research of Institute of the college fund/ UNCF.

Phuntsog, N. (2001). Culturally responsive teaching: What do selected United States elementary school teachers think? Intercultural Education, 12, 51-64. doi:10.1080/14675980120033966

Posner, G., Strike, K., Hewson, P., \& Gertzog, W. (1982). Accommodation of a scientific conception: Toward a theory of conceptual change. Science Education, 66, 211-227. doi:10.1002/sce.3730660207

Rosebery, A., Warren, B., \& Conant, F. (1992). Appropriating scientific discourse: Findings from language minority classrooms. The Journal of the Learning Sciences, 2, 61-94. doi:10.1207/s15327809jls0201_2

Sadler, T. D., Amirshokoohi, A., Kazempour, M., \& Allspaw, K. M. (2006). Socioscience and ethics in science classrooms: Teacher perspectives and strategies. Journal of Research in Science Teaching, 43, 353-376. doi:10.1002/tea.20142

Stinson, D. (2004). Mathematics as "Gate-Keeper” (?): Three theoretical perspectives that aim toward empowering all children with a key to the gate. The Mathematics Educator, 14, 8-18.

Tate, W. (1995). Returning to the root: A culturally relevant approach to mathematics pedagogy. Theory into Practice, 34, 166-173. doi:10.1080/00405849509543676

Thomas, M. (2006). Building the culturally relevant standards-based social studies classroom. Southern Social Studies Journal, 31, 47-61.

Warren, B., Rosebery, A., \& Conant, F. (1989). Cheche konnen: Science and literacy in language minority classrooms. Newton, MA: Bolt, Beranek, \& Newman.

Weiss, I., \& Pasley, J. (2004). What is high-quality instruction? Educational Leadership, 61, 24-28.

Yin, R. K. (2008). Case study research: Design and methods (4th ed.). Thousand Oakes, CA: Sage Publications. 